\title{
Potential impact of a nine-valent vaccine in human papillomavirus related cervical disease
}

\author{
Beatriz Serrano ${ }^{1}$, Laia Alemany ${ }^{1,2}$, Sara Tous ${ }^{1}$, Laia Bruni ${ }^{1}$, Gary M Clifford ${ }^{3}$, Thomas Weiss ${ }^{4}$,
} Francesc Xavier Bosch ${ }^{1}$ and Silvia de Sanjosé ${ }^{1,2^{*}}$

\begin{abstract}
Background: Information on human papillomavirus (HPV) type distribution is necessary to evaluate the potential impact of current and future HPV vaccines. We estimated the relative contribution (RC) to invasive cervical cancer (ICC) and precancerous cervical lesions of the nine HPV types (HPV 6/11/16/18/31/33/45/52/58) included in an HPV vaccine currently under development.
\end{abstract}

Methods: Estimations on ICC were based on an international study of 8,977 HPV positive cases and estimations on precancerous cervical lesions were extracted from a published meta-analysis including 115,789 HPV positive women. Globocan 2008 and 2010 World Population Prospects were used to estimate current and future projections of new ICC cases.

Results: RC of the 9 HPV types in ICC was 89.4\%, with $18.5 \%$ of cases positive for HPV 31/33/45/52/58. Regional variations were observed. RCs varied by histology, ranging between $89.1 \%$ in squamous cell carcinomas (SCC) and 95.5\% in adenocarcinomas (ADC). HPV 16/18/45 were detected in 94.2\% of ADC. RC of the 9 types altogether decreased with age (trend test $p<0.0001$ ), driven by the decrease in older ages of HPV 16/18/45. In contrast, the RC of HPV 31/33/52/58 increased with age. Due to population growth alone, projected estimates of ICC cases attributable to the 9 types are expected to rise from 493,770 new cases in 2012 to 560,887 new cases in 2025. The RCs of individual high risk HPV types varied by cytological and histological grades of HPV-positive precancerous cervical lesions, and there was an under representation of HPV 18 and 45 compared to ICC.

Conclusions: The addition of HPV 31/33/45/52/58 to HPV types included in current vaccines could prevent almost $90 \%$ of ICC cases worldwide. If the nine-valent vaccine achieves the same degree of efficacy than previous vaccines, world incidence rates could be substantially reduced.

Keywords: Human papillomavirus, Cervical cancer, Genotype, Epidemiology, Human papillomavirus vaccines

\section{Background}

Cervical cancer and other HPV related cancers represent an important global public health problem, both in more and less developed countries. Cervical cancer is the third most common cancer among women worldwide, with an estimated 530,000 new cases and 275,000 new deaths in 2008. More than $85 \%$ of the global cervical cancer burden occurs in developing countries and in 12 of the

\footnotetext{
* Correspondence: s.sanjose@iconcologia.net

${ }^{1}$ Unit of Infections and Cancer (UNIC), Cancer Epidemiology Research Program (CERP), IDIBELL, Institut Català d'Oncologia (ICO) - Catalan Institute of Oncology, Gran Via de l'Hospitalet, 199-203, L'Hospitalet de Llobregat, Barcelona, Spain

${ }^{2}$ CIBER Epidemiología y Salud Pública, CIBERESP, Pamplona, Spain

Full list of author information is available at the end of the article
}

22 regions of the world, cervical cancer remains the first or second most common female cancer [1].

HPV carcinogenicity has been convincingly established for cervical cancer and it is generally accepted that HPV infection is necessary for the development of invasive cervical cancer (ICC) [2]. The International Agency for Research on Cancer (IARC) has classified HPV 16 and 18 as cervical carcinogens since 1995 . By 2011 the group was expanded to include HPV 31/33/35/39/45/51/52/ $56 / 58 / 59$ [3]. It is estimated that over $50-80 \%$ of sexually active women will be infected with one or more genital HPV types during their lives, with peak prevalence in young sexually active individuals [3-5].

\section{Biomed Central}

(c) 2012 Serrano et al.; licensee BioMed Central Ltd. This is an Open Access article distributed under the terms of the Creative Commons Attribution License (http://creativecommons.org/licenses/by/2.0), which permits unrestricted use, distribution, and reproduction in any medium, provided the original work is properly cited. 
HPV prophylactic vaccines using virus like particles (VLP) have been recognized as a major advance and the most effective intervention to control for HPV and cervical cancer [4]. Current licensed HPV vaccines, a bivalent (CervarixTM) and a quadrivalent $\mathrm{HPV}$ vaccine $\left(\right.$ Gardasil $\left.^{\circledR}\right)$ are designed to prevent HPV infection and HPV-related disease. CervarixTM was designed to prevent infection by HPV types $16 / 18$, which cause about 70 percent of cervical cancer cases $[6,7]$, and Gardasil ${ }^{\circledR}$ targets the same two cancer causing types and, in addition, is intended to prevent infection by HPV 6/11, which cause close to $90 \%$ of external genital wart cases [8]. These vaccines are near 100\% effective in stimulating the immune system against the strains targeted in the vaccine when administered in a 3 dose course [9]. Given the high safety and efficacy of both vaccines, many countries have licensed and some have already included them in their national immunization programs, but they are yet to reach women in most low-income countries [10]. In addition, the GAVI Alliance has announced country applications for national introduction of HPV at very low price aiming feasibility and sustainability of such vaccines even in the very poor settings [11,12].

Future impact of HPV vaccination with current commercialized vaccines has been largely modelled $[13,14]$. Models predict a substantial reduction in prevalence of specific HPV 16/18 infections, followed by a reduction in cervical abnormalities and a final reduction in ICC, if coverage is high $(>70 \%)$ and vaccine induced protection lasts for at least 10 years [4]. The greatest impact is expected in low-income and middle-income countries where there is no screening or only limited screening for cervical cancer and where the highest burden of cervical disease is generally observed [4]. Impact of vaccination with current HPV vaccines in low resource settings, without any other preventive actions, is estimated to potentially reduce cancer risk by $40-50 \%$ at $70 \%$ vaccination coverage, with a potential reduction in the next decade of more than 4 million deaths among vaccinated women $[14,15]$.

After HPV 16/18, data confirm HPV 31/33/35/45/52/ 58 as the most frequently detected types in ICC worldwide [6,7]. Merck is developing a recombinant ninevalent vaccine, code named V503, that also uses virus like particles (VLP). V503 contains 5 additional HPV types $(31 / 33 / 45 / 52 / 58)$ to the $4 \mathrm{HPV}$ types previously included in Gardasil ${ }^{\circledR}$ and has successfully completed several studies. Phase III studies are ongoing [16].

The aim of the present article is to estimate the potential impact of a new nine-valent vaccine in HPV-related cervical disease by summarizing the evidence on specific relative contribution (RC) of the $9 \mathrm{HPV}$ types (HPV 6/ $11 / 16 / 18 / 31 / 33 / 45 / 52 / 58)$ in ICC and precancerous cervical lesions, in the pre-vaccination era.

\section{Methods}

To estimate the RC of the 9 HPV types included in the V503 Merck's investigational HPV vaccine, we used data from an international study on HPV in ICC [7] and the most recent meta-analysis in precancerous cervical lesions available in the literature [17].

\section{Cervical cancer}

The estimations on RC in ICC were based on data from a retrospective cross-sectional study carried out at Catalan Institute of Oncology, Spain (ICO) in collaboration with DDL laboratory, The Netherlands, to estimate the distribution of HPV types in women with ICC between 1949 and 2009 [7]. Briefly, the study included information from 10,575 ICC cases, and 8,977 (85\%) of them were positive for HPV DNA. Paraffin-embedded specimens from consecutive cases (aged 16-97 years) with ICC were obtained from hospital pathology archives in 38 countries-Europe (Bosnia-Herzegovina, Croatia, Czech Republic, France, Greece, Italy, Netherlands, Poland, Portugal, and Spain); North America (USA); Central and South America (Argentina, Brazil, Chile, Colombia, Guatemala, Honduras, Mexico, Paraguay, Peru, and Venezuela); Africa (Algeria, Mozambique, Nigeria, and Uganda); Asia (Bangladesh, China, India, Israel, Japan, South Korea, Kuwait, Lebanon, Philippines, Taiwan, Thailand, and Turkey); and Oceania (Australia). After the blocks were processed, inclusion criteria were a pathological confirmation of a primary ICC of epithelial origin in the tissue sample selected for analysis of HPV DNA. HPV DNA detection was done by PCR with SPF-10 broadspectrum primers followed by DNA enzyme immunoassay and genotyping with a reverse hybridization line probe assay - LiPA25 that detects 25 high-risk (HR) and low-risk (LR) HPV types (6/11/16/18/31/33/34/35/39/40/42/43/44/ $45 / 51 / 52 / 53 / 54 / 56 / 58 / 59 / 66 / 68 / 70 / 74)$. Sequence analysis was done to characterize HPV-positive samples with unknown HPV types. If no HPV type could be attributed after DNA sequencing, the HPV was labelled HPV undetermined (52 cases out of 8,977 (0.6\%)). All protocols were approved by the local and ICO ethics committees, and the entire study progress was overseen by an international steering committee.

RC of the $9 \mathrm{HPV}$ types included in the nine-valent vaccine (HPV 6/11/16/18/31/33/45/52/58) in ICC was expressed as the proportion of women positive for a given type among all the HPV-positive samples. The availability of HPV-disaggregated data made possible the calculation of RCs for HPV types alone or for the groups of HPV types. Multiple infections were added to single types in accordance with a proportional weighting attribution $[18,19]$. For example, if two ICC lesions found to test positive for both HPV 16 and 45 in a region of the world, and there were 9 cases infected by HPV-16 as a 
single type and 1 case infected by HPV 45 as a single type, then $[2 * 9 /(9+1)]$ or 1.8 of these two multi-type infected lesions would be attributed to HPV 16 and $[2 * 1 /(9+1)]$ or 0.2 attributed to HPV 45

Subjects were classified into 10 geographical regions defined by the United Nations Population Divisions (Africa, Asia, Eastern Asia, Western/Central Asia, Europe, North America, Latin America, Central America, South America and Oceania). RC was provided for the following histological categories: Squamous Cell Carcinoma (SCC), Adenocarcinoma (ADC), Adenosquamous Cell Carcinoma (ADSCC) and Other histology that included undifferentiated, neuroendocrine, not otherwise specified, basal adenoid and cystic adenoid carcinomas. Estimations of HPV RCs by age groups were also provided. Evaluations of the trends by age were determined by trend test analysis. Statistically significant $\mathrm{p}$-value for this analysis was set at 0.05 level.

Projections of new ICC cases attributed to HPV 16/18 and HPV 31/33/45/52/58 were calculated for year 2012 and projected to year 2025, worldwide and by region. Estimations were based on the following assumptions and data sources: a) Oncogenic HPV types may be detected in virtually all cases of cervical cancer, being generally accepted that the virus is necessary for the development of cancer, so the RC of all HPV types altogether is assumed to be $100 \%$. Therefore, we assumed that the attributional fraction (AF) for each HPV type in ICC corresponded to the RC in ICC. The overall $R C$ was used as the world AF, without weighting regional estimations; b) Globocan 2008 incidence rates were used with the assumption that these rates will apply in the future [1]; c) We used the appropriate population forecast available in the latest World Population Prospects (revision 2010) [20]. Impact of vaccination was not taken into account.

\section{Precancerous cervical lesions}

The estimations on RCs in precancerous cervical lesions were based on data from a recent IARC meta-analysis [17]. Briefly, this meta-analysis included information on HPV type distribution in 115,789 HPV-positive women from 423 PCR-based studies worldwide. Inclusion criteria were use of broad-spectrum consensus PCR-assays based on the primers MY09/11, PGMY09/11, GP5+/6+, SPF10, SPF1/GP6 or L1C1/L1C2, and information of overall and type-specific HPV prevalence, by strata of cyto- and/or histo-pathological cervical diagnoses. LR HPV types were not included in the meta-analysis, so specific information for HPV 6 and 11 was not provided. Data were extracted from the manuscript for 12,983 cases $(52 \%$ of which were HPV-positive) of atypical squamous cells of undetermined significance (ASCUS), 17,805 cases (76\% HPV-positive) of low-grade squamous intraepithelial lesions (LSIL), and 7,743 cases (85\% HPV- positive) of high-grade SIL (HSIL) diagnosed cytologically, 11,043 cases (73\% HPV-positive) of cervical intraepithelial neoplasia grade 1 (CIN1), 4,754 cases (86\% HPV-positive) of CIN2 and 11,618 cases (93\% HPV-positive) of CIN3 diagnosed histologically. As described in the manuscript [17], in order to retain appropriate sample size for comparisons between regions, precancerous cervical lesions were collapsed in two categories; Low-grade, encompassing ASCUS, LSIL and CIN1; and High-grade, including HSIL, CIN2 and CIN3.

The RCs of the 7 individual HR HPV types (16/18/31/ $33 / 45 / 52 / 58$ ) were expressed as the proportion of samples positive for a given type among all the HPV-positive samples tested for the mentioned type, therefore denominators vary by type. Individual-level data on HPV types in multiple infections were not available, so RC includes single and multiple infections and the total sum of RCs of the 7 HR HPV can exceed 100\%. Subjects were classified into seven geographical regions defined by the United Nations Population Divisions (Africa, Eastern Asia, Western/Central Asia, Europe, North America, South/ Central America and Oceania) [17].

In an attempt to estimate a combined RC estimation of the $7 \mathrm{HR}$ HPV types altogether for CIN2/3 or HSIL lesions similar to that in ICC, we used Smith et al. metaanalysis [21] (for studies published from 2002 to 2006) and Guan et al. meta-analysis [17] (for studies from 2006-2011) as data sources to identity papers providing detailed data for single and multiple infections. We established the following criteria for eligibility: (i) inclusion of at least 75 cases of HSIL, CIN2 or CIN3, (ii) use of broad-spectrum PCR, and (iii) reporting of type-specific HPV prevalence for at least the $7 \mathrm{HR}$ HPV genotypes (HPV 16/18/31/33/45/52/58) included in the nine-valent Merck's vaccine. Forty seven studies met inclusion criteria, including a total of 14,039 cases with an overall HPV prevalence of $89.7 \%$. Assessment of the RC of the $7 \mathrm{HR}$ HPV types altogether was only possible in 13 studies (including 4,101 cases) where individual-level data on HPV types in multiple infections was available.

\section{Results}

\section{Cervical cancer}

Combined RC of the $9 \mathrm{HPV}$ types included in the ninevalent vaccine (HPV 16/18/31/33/45/52/58/6/11) worldwide was $89.4 \%$ (95\%CI: $88.8-90.1)$, with some regional variations, from $84.6 \%$ (95\%CI: 81.9-87.1) in Central America to $95.5 \%$ (95\%CI: 91.2-98.2) in North America. HPV 16/18 were the most common types accounting for almost 70\% worldwide, except for Central America and North America where a RC of $64.4 \%$ (95\%CI: 60.9-67.8) and $78.8 \%$ (95\%CI: 71.6-84.8) were observed respectively. The additional $\mathrm{RC}$ of the other 5 high risk HPV types (HPV 31/33/45/52/58) was $18.5 \%$ (95\%CI: 17.7-19.3); 
Table 1 Relative contribution of HPV 16/18/31/33/45/52/58 in cases of ICC HPV-positive, by region

\begin{tabular}{|c|c|c|c|c|c|c|c|c|c|c|c|}
\hline & $\overline{(n=8,977)}$ & $\overline{(n=544)}$ & $(n=2,641)$ & $\begin{array}{c}\text { Western/ } \\
\text { Central } \\
\text { Asia } \\
(n=836)\end{array}$ & $\begin{array}{c}\begin{array}{c}\text { Eastern } \\
\text { Asia }\end{array} \\
(n=1,805)\end{array}$ & $\begin{array}{c}\text { Latin } \\
\text { America }\end{array}$ & $\begin{array}{c}\begin{array}{c}\text { South } \\
\text { America }\end{array} \\
(n=2,629)\end{array}$ & $\begin{array}{c}\begin{array}{c}\text { Central } \\
\text { America }\end{array} \\
(n=775)\end{array}$ & $\begin{array}{c}\begin{array}{c}\text { North } \\
\text { America }\end{array} \\
(n=160)\end{array}$ & $(n=2,058)$ & Oceania \\
\hline & $\begin{array}{c}\mathrm{RC} \% \\
(95 \% \mathrm{Cl})\end{array}$ & $\begin{array}{c}\mathrm{RC} \% \\
(95 \% \mathrm{Cl})\end{array}$ & $\begin{array}{c}\mathrm{RC} \% \\
(95 \% \mathrm{Cl})\end{array}$ & $\begin{array}{c}\mathrm{RC} \% \\
(95 \% \mathrm{Cl})\end{array}$ & $\begin{array}{c}\mathrm{RC} \% \\
(95 \% \mathrm{Cl})\end{array}$ & $\begin{array}{c}\mathrm{RC} \% \\
(95 \% \mathrm{Cl})\end{array}$ & $\begin{array}{c}\mathrm{RC} \% \\
(95 \% \mathrm{Cl})\end{array}$ & $\begin{array}{c}\mathrm{RC} \% \\
(95 \% \mathrm{Cl})\end{array}$ & $\begin{array}{c}\mathrm{RC} \% \\
(95 \% \mathrm{Cl})\end{array}$ & $\begin{array}{c}\mathrm{RC} \% \\
(95 \% \mathrm{Cl})\end{array}$ & $\begin{array}{c}\text { RC \% } \\
(95 \% \mathrm{Cl})\end{array}$ \\
\hline \multicolumn{12}{|c|}{ Combinations of HPV types } \\
\hline 9 HPV types* & $\begin{array}{c}89.4 \\
(88.8-90.1)\end{array}$ & $\begin{array}{c}86.9 \\
(83.8-89.7)\end{array}$ & $\begin{array}{c}91.5 \\
(90.4-92.5)\end{array}$ & $\begin{array}{c}92.0 \\
(89.9-93.7)\end{array}$ & $\begin{array}{c}91.3 \\
(89.9-92.6)\end{array}$ & $\begin{array}{c}88.2 \\
(87.0-89.2)\end{array}$ & $\begin{array}{c}89.2 \\
(87.9-90.3)\end{array}$ & $\begin{array}{c}84.6 \\
(81.9-87.1)\end{array}$ & $\begin{array}{c}95.5 \\
(91.2-98.2)\end{array}$ & $\begin{array}{c}89.1 \\
(87.7-90.4)\end{array}$ & $\begin{array}{c}89.4 \\
(83.8-93.6)\end{array}$ \\
\hline $16 / 18$ & $\begin{array}{c}70.8 \\
(69.8-71.7)\end{array}$ & $\begin{array}{c}70.3 \\
(66.2-74.0)\end{array}$ & $\begin{array}{c}71.6 \\
(69.8-73.4)\end{array}$ & $\begin{array}{c}77.5 \\
(74.5-80.3)\end{array}$ & $\begin{array}{c}68.9 \\
(66.7-71.1)\end{array}$ & $\begin{array}{c}68.2 \\
(66.6-69.8)\end{array}$ & $\begin{array}{c}69.4 \\
(67.6-71.1)\end{array}$ & $\begin{array}{c}64.4 \\
(60.9-67.8)\end{array}$ & $\begin{array}{c}78.8 \\
(71.6-84.8)\end{array}$ & $\begin{array}{c}72.8 \\
(70.8-74.7)\end{array}$ & $\begin{array}{c}78.2 \\
(71.3-84.2)\end{array}$ \\
\hline $31 / 33 / 45 / 52 / 58$ & $\begin{array}{c}18.5 \\
(17.7-19.3)\end{array}$ & $\begin{array}{c}16.7 \\
(13.7-20.1)\end{array}$ & $\begin{array}{c}19.8 \\
(18.3-21.3)\end{array}$ & $\begin{array}{c}14.5 \\
(12.2-17.0)\end{array}$ & $\begin{array}{c}22.3 \\
(20.4-24.3)\end{array}$ & $\begin{array}{c}19.8 \\
(18.5-21.2)\end{array}$ & $\begin{array}{c}19.6 \\
(18.1-21.2)\end{array}$ & $\begin{array}{c}20.3 \\
(17.5-23.3)\end{array}$ & $\begin{array}{c}16.9 \\
(11.4-23.6)\end{array}$ & $\begin{array}{c}16.2 \\
(14.6-17.8)\end{array}$ & $\begin{array}{c}8.8 \\
(5.0-14.1)\end{array}$ \\
\hline Other Types & $\begin{array}{c}10.6 \\
(9.9-11.2)\end{array}$ & $\begin{array}{c}13.0 \\
(10.3-16.2)\end{array}$ & $8.5(7.5-9.6)$ & $\begin{array}{c}8.0 \\
(6.3-10.1)\end{array}$ & $\begin{array}{c}8.7 \\
(7.4-10.1)\end{array}$ & $\begin{array}{c}11.8 \\
(10.8-13.0)\end{array}$ & $\begin{array}{c}10.9 \\
(9.7-12.1)\end{array}$ & $\begin{array}{c}15.4 \\
(12.9-18.1)\end{array}$ & $4.6(1.8-8.8)$ & $\begin{array}{c}10.9 \\
(9.6-12.3)\end{array}$ & $\begin{array}{c}10.6 \\
(6.4-16.2)\end{array}$ \\
\hline \multicolumn{12}{|c|}{ Specific HPV types } \\
\hline 16 & $\begin{array}{c}60.5 \\
(59.5-61.6)\end{array}$ & $\begin{array}{c}47.7 \\
(43.3-51.9)\end{array}$ & $\begin{array}{c}60.5 \\
(58.6-62.3)\end{array}$ & $\begin{array}{c}66.7 \\
(63.3-69.8)\end{array}$ & $\begin{array}{c}57.6 \\
(55.3-59.9)\end{array}$ & $\begin{array}{c}59.2 \\
(57.5-70.9)\end{array}$ & $\begin{array}{c}61.3 \\
(59.4-63.2)\end{array}$ & $\begin{array}{c}52.0 \\
(48.4-55.6)\end{array}$ & $\begin{array}{c}71.9 \\
(64.2-78.9)\end{array}$ & $\begin{array}{c}65.5 \\
(63.4-67.6)\end{array}$ & $\begin{array}{c}58.6 \\
(51.0-66.3)\end{array}$ \\
\hline 18 & $\begin{array}{c}10.3 \\
(9.6-10.9)\end{array}$ & $\begin{array}{c}22.6 \\
(19.2-26.4)\end{array}$ & $\begin{array}{c}11.2 \\
(10.0-12.4)\end{array}$ & $\begin{array}{c}10.8 \\
(8.9-13.2)\end{array}$ & $\begin{array}{c}11.3 \\
(9.9-12.9)\end{array}$ & $\begin{array}{c}9.1 \\
(8.1-10.1)\end{array}$ & $8.1(7.1-9.2)$ & $\begin{array}{c}12.5 \\
(10.3-15.1)\end{array}$ & $\begin{array}{c}6.9 \\
(3.48-11.8)\end{array}$ & $7.3(6.2-8.5)$ & $\begin{array}{c}19.9 \\
(14.3-26.8)\end{array}$ \\
\hline 31 & $3.7(3.3-4.1)$ & $1.9(0.9-3.4)$ & $3.0(2.4-3.8)$ & $2.8(1.6-4.0)$ & $3.2(2.4-4.1)$ & $\begin{array}{c}4.9 \\
(4.2-5.7)\end{array}$ & $6.5(5.6-7.6)$ & $4.3(3.0-5.9)$ & $3.4(1.0-7.1)$ & $3.4(2.7-4.3)$ & $0.7(0.0-3.2)$ \\
\hline 33 & $3.8(3.4-4.3)$ & $1.5(0.6-2.9)$ & $3.5(2.8-4.3)$ & $2.5(1.6-3.8)$ & $4.0(3.1-4.9)$ & $\begin{array}{c}3.5 \\
(3.2-4.5)\end{array}$ & $5.0(4.3-6.0)$ & $2.9(1.9-4.4)$ & $3.1(1.0-7.1)$ & $5.7(4.7-6.8)$ & $2.1(0.4-5.1)$ \\
\hline 45 & $5.9(5.4-6.4)$ & $\begin{array}{c}9.9 \\
(7.6-12.8)\end{array}$ & $5.5(4.7-6.5)$ & $7.0(5.4-9.0)$ & $4.9(3.9-6.0)$ & $\begin{array}{c}6.8 \\
(5.9-7.7)\end{array}$ & $3.7(3.0-4.4)$ & $7.5(5.7-9.6)$ & $\begin{array}{c}5.4 \\
(2.6-10.4)\end{array}$ & $3.9(3.1-4.8)$ & $5.5(2.5-9.8)$ \\
\hline 52 & $2.8(2.5-3.2)$ & $2.6(1.4-4.3)$ & $3.8(3.1-4.6)$ & $0.8(0.3-1.7)$ & $5.3(4.3-6.4)$ & $\begin{array}{c}2.7 \\
(2.2-3.3)\end{array}$ & $3.0(2.4-3.7)$ & $1.6(0.9-2.9)$ & $2.9(1.0-7.1)$ & $1.9(1.4-2.6)$ & $0.6(0.0-3.2)$ \\
\hline 58 & $2.3(2.0-2.6)$ & $0.7(0.2-1.9)$ & $3.9(3.2-4.7)$ & $1.3(0.7-2.3)$ & $5.0(4.1-6.2)$ & $\begin{array}{c}2.0 \\
(3.3-2.5)\end{array}$ & $1.4(1.0-2.0)$ & $3.9(2.6-5.5)$ & $\begin{array}{c}1.9 \\
(0.39-5.4)\end{array}$ & $1.3(0.9-1.9)$ & $0.0(0.0-2.2)$ \\
\hline 6 & $0.1(0.1-0.2)$ & $0.0(0.0-0.7)$ & $0.0(0.0-0.2)$ & $0.0(0.0-0.4)$ & $0.1(0.0-0.3)$ & $0.1(0.0-0.3)$ & $0.1(0.0-0.3)$ & $0.0(0.0-0.5)$ & $0.0(0.0-2.3)$ & $0.2(0.0-0.4)$ & $1.8(0.4-5.1)$ \\
\hline 11 & $0.0(0.0-0.1)$ & $0.0(0.0-0.7)$ & $0.0(0.0-0.2)$ & $0.0(0.0-0.4)$ & $0.1(0.0-0.3)$ & $0.0(0.0-0.2)$ & $0.0(0.0-0.2)$ & $0.0(0.0-0.5)$ & $0.0(0.0-2.3)$ & $0.0(0.0-0.2)$ & $0.0(0.0-2.2)$ \\
\hline
\end{tabular}

"ICC": Invasive cervical cancer; "RC": Relative Contribution; "95\%Cl”: 95\% Confidence Interval; * "9 HPV types" includes the ones in nine-valent vaccine: HPV 16/18/31/33/45/52/58/6/11.

Additional information: Available data are from unvaccinated women (pre-vaccination period).

Type specific RC estimations: Numerator = single infections + proportional attribution of multiple types; Denominator = HPV DNA positive cervical cancer cases 
ranging from $8.8 \%$ (95\%CI: $5.0-14.1$ ) in Oceania to $22.3 \%$ (95\%CI: 20.4-24.3) in Eastern Asia. HPV 45 was the most frequently detected type after HPV 16 and 18 worldwide except in Eastern Asia where RCs of HPV 52/58 were higher, and in Europe where RC of HPV 33 was higher. RC of HPV 45 was especially prominent in Africa (9.9\%; 95\% CI: 7.6-12.8), Western Asia (7.0\%; 95\%CI: 5.4-9.0) and Latin-America (6.8\%; 95\%CI: 5.9-7.7). HPV 31 was relatively more prevalent in Latin-America (4.9\%; 95\%CI: 4.2-5.7) and HPV 33 was more prevalent in Europe (5.7\%; 95\%CI: 4.7-6.8), as previously remarked. Infections by HPV 52/58 were more usually diagnosed in Eastern Asia (5.3\%; 95\%CI: 4.3-6.4 and 5.0\%; 95\%CI: 4.1-6.2, respectively). Addition of HPV 6/11 did not modify the cancer burden estimates (RC: $0.1 \%$ ) (Table 1).

Regarding histological diagnosis, the combined RC of the $9 \mathrm{HPV}$ types ranged from $89.1 \%$ (95\%CI: 88.4-89.7) in SCC to $95.5 \%$ (95\%CI: 93.3-97.2) in ADC. HPV 16/ $18 / 45$ were consistently the three most common types in all histological categories accounting for $94.2 \%$ (95\% CI: 91.7-96.2) of ADC cases compared to the $75.4 \%$ (95\%CI: 74.5-76.3) contribution in SCC. A greater contribution of HPV 18/45 was observed in ADC, ADSCC and other histologies compared to that in SCC and conversely, HPV 16 RC was higher in SCC. Substantial differences in the RCs by histological category were observed for the other HPV types, with much higher contributions of HPV 31/33/52/58 in SCC (RC: 13.6\%) and ADSCC (RC: $7.2 \%)$ compared to the $\mathrm{RC}$ of less than $1 \%$ and $3 \%$ observed in ADC cases and other histologies, respectively (Figure 1).

The $\mathrm{RC}$ of the 9 types altogether decreased with age (trend test $\mathrm{p}<0.0001$ ); however, this was mainly explained by the decrease in older ages of HPV 16/18/45. In contrast, ICC cases in women positive for HPV 31/33/52/58 increased with age (trend test $\mathrm{p}<0.0001$ ), although HPV $16 / 18 / 45$ were also the most common types in older ages. Remarkable differences were found in ICC cases positive for HPV types other than those included in the ninevalent vaccine, with $\mathrm{RCs}$ ranging from $4.2 \%$ (95\%CI: $0.5-14.3)$ in women aged less than 25 years to $19.4 \%$ (95\% CI: 13.7-26.0) in women older than 80 years (Figure 2).

Without changes in prevention and control, and only due to population growth, projections for the next years reveal a growing burden of cervical cancer. Projected global estimates of ICC cases, not taking into account the impact of vaccination and assuming that all cases are related to $\mathrm{HPV}$ infection, are expected to rise to 627,354 new cases in 2025, with 444,167 cases attributable to HPV $16 / 18$ and 116,061 cases attributable to HPV $31 / 33 / 45 / 52 / 58$. Over $60 \%$ of cases will come from Asia, $16 \%$ from Africa and $13 \%$ from Latin America (Table 2).

\section{Precancerous cervical lesions}

RCs of individual HR HPV types varied by cytological and histological grade of HPV-positive precancerous cervical lesions.

HPV 16 was the most frequently detected HR type in every grade of cervical lesion. Its importance increased with the severity of the lesion, with RCs of $47.5 \%$ (95\% CI: 46.3-48.7) in HPV-positive HSIL and 58.2\% (95\%CI: 57.3-59.1) in HPV-positive CIN3 diagnoses. HPV 45 was consistently detected less often than other HR types included in the nine-valent vaccine in all cytological and histological categories (Figure 3).

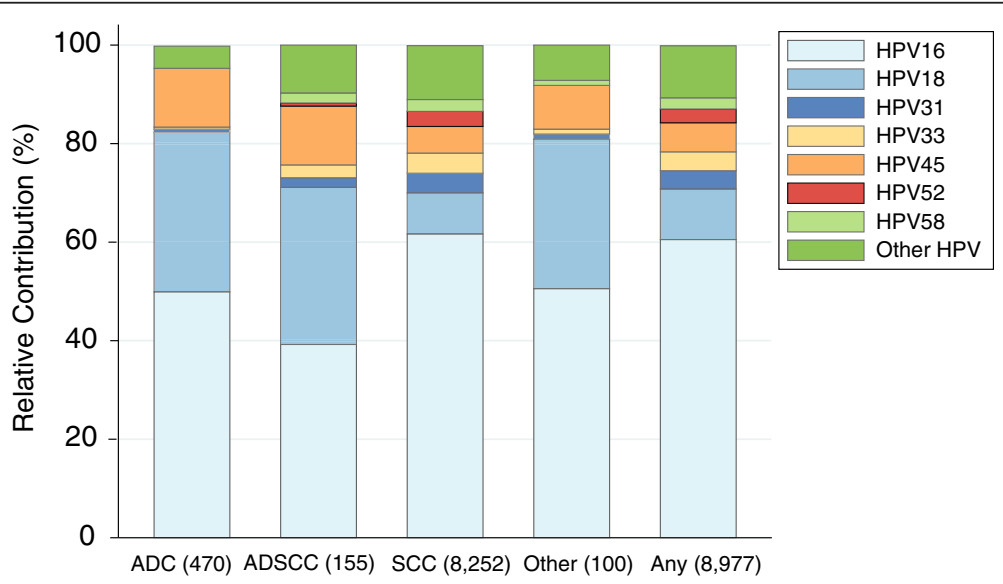

Figure 1 Relative contribution of HPV 16/18/31/33/45/52/58 in cases of ICC HPV-positive, by histology. "ICC": Invasive cervical cancer; "SCC": Squamous cell carcinoma; "ADC": Adenocarcinoma; "ADSCC": Adenosquamous cell carcinoma; "Other": Includes undifferentiated, neuroendocrine, not otherwise specified, basal adenoid and cystic adenoid carcinomas. Additional information: Available data are from unvaccinated women (pre-vaccination period). Type specific relative contribution estimations: Numerator $=$ single infections + proportional attribution of multiple types; Denominator = HPV DNA positive cervical cancer cases. The number of cases by histology is shown in " ()$^{\prime}$. Specific information on HPV 6 and 11 is not included due to the low relative contribution of these types. 

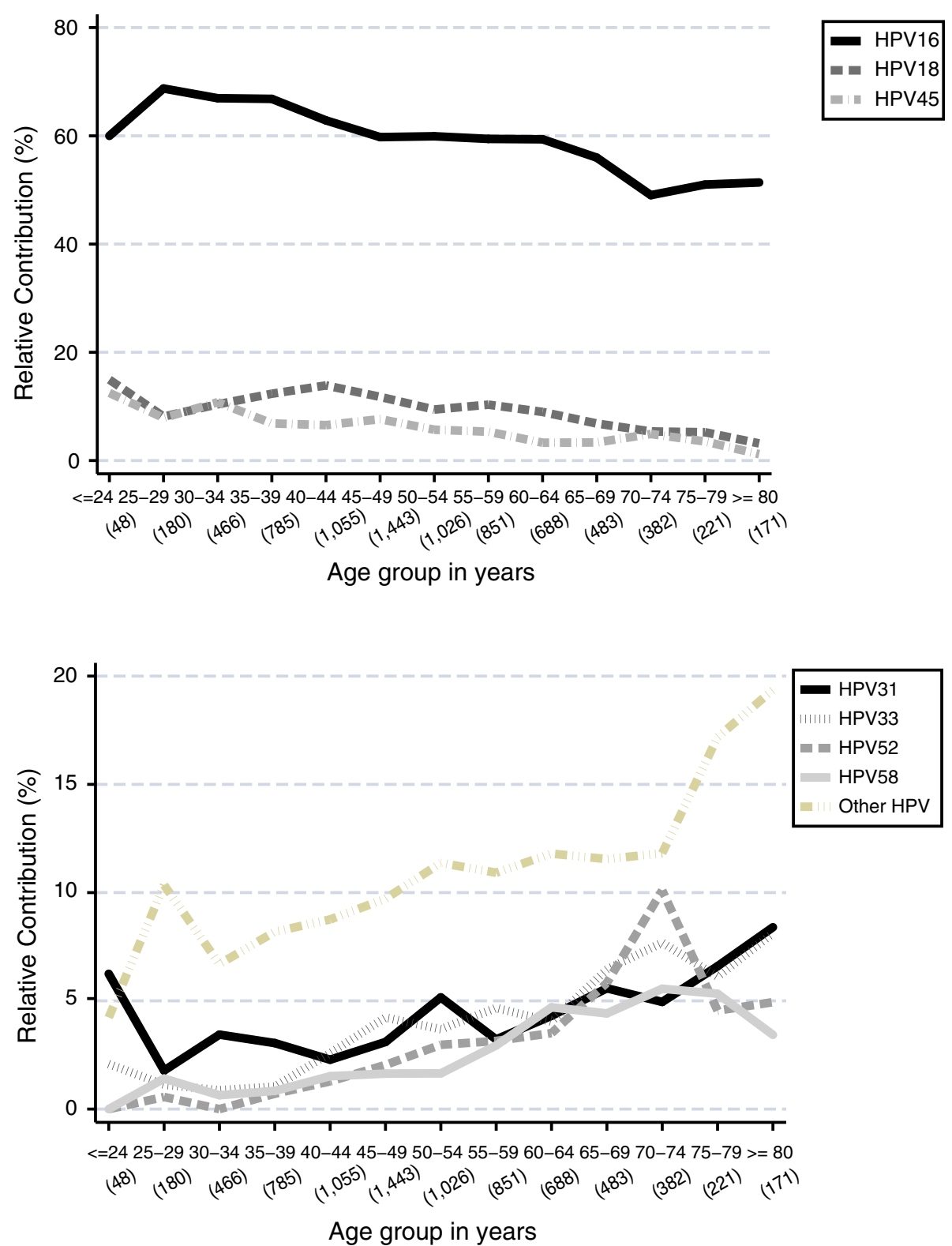

Figure 2 Relative contribution of HPV 16/18/45/31/33/52/58 and other types in ICC cases HPV-positive, by age group. "ICC": Invasive cervical cancer; Additional information: Available data are from unvaccinated women (pre-vaccination period). Type specific relative contribution estimations: Numerator = single infections + proportional attribution of multiple types; Denominator = HPV DNA positive cervical cancer cases. The number of cases by age group is shown in "( )". Specific information on HPV 6 and 11 is not included due to the low relative contribution of these types.

Regional variations in the RCs of precancerous cervical lesions due to each HR HPV type were also observed. HPV 16 was the most common type in all regions in both low-grade and high-grade lesions. RC in HPVpositive high-grade lesions ranged from $30.3 \%$ to $60.3 \%$. HPV 45 was the less frequently detected HR type in the majority of regions of the world (including Africa, where we found it to be an important HPV type in ICC). Regarding HPV-positive high-grade lesions, HPV 31 was relatively more prevalent in Western and Central Asia, and similarly to that found in ICC; HPV 52/58 showed higher RCs in Eastern Asia (Table 3).

In the review of published papers in order to assess the RC of the 7 HR HPV types altogether for CIN $2 / 3$ or HSIL lesions, extraction of detailed data of single and multiple infections was possible in 4,101 cases (13 studies). Similar to ICC lesions, multiple infections were added to single types in accordance with a proportional weighting attribution. Multiple infections were higher in included studies compared to that in not included studies $(41.3 \%$ vs 
Table 2 Burden of ICC attributable to HPV 16/18 and HPV 31/33/45/52/58 in 2012, projected to 2025; by region

\begin{tabular}{|c|c|c|c|c|c|c|}
\hline \multirow[t]{3}{*}{ Region } & \multicolumn{2}{|c|}{ HPV RC (\%) } & \multicolumn{4}{|c|}{ Attributable new cases $(\mathrm{N})$} \\
\hline & \multirow[t]{2}{*}{$16 / 18$} & \multirow[t]{2}{*}{$31 / 33 / 45 / 52 / 58$} & \multicolumn{2}{|c|}{ Year 2012} & \multicolumn{2}{|c|}{ Year 2025} \\
\hline & & & $16 / 18$ & $31 / 33 / 45 / 52 / 58$ & $16 / 18$ & $31 / 33 / 45 / 52 / 58$ \\
\hline World & 70.8 & 18.6 & 391,016 & 102,172 & 444,167 & 116,061 \\
\hline Africa & 70.3 & 16.7 & 60,925 & 14,438 & 80,556 & 19,090 \\
\hline Asia & 71.7 & 19.8 & 232,046 & 63,986 & 259,130 & 71,454 \\
\hline Eastern Asia & 68.9 & 22.3 & 95,505 & 30,869 & 100,950 & 32,629 \\
\hline Western/Central Asia & 77.5 & 14.5 & 145,101 & 27,073 & 171,333 & 31,967 \\
\hline Latin-America & 68.3 & 19.8 & 48,777 & 14,142 & 54,973 & 15,938 \\
\hline South America & 69.4 & 19.6 & 34,632 & 9,799 & 38,783 & 10,973 \\
\hline Central America & 64.4 & 20.2 & 13,602 & 4,264 & 15,522 & 4,866 \\
\hline North America & 78.7 & 16.6 & 9,913 & 2,094 & 10,913 & 2,305 \\
\hline Europe & 72.8 & 16.2 & 39,880 & 8,867 & 39,924 & 8,877 \\
\hline Oceania & 78.5 & 8.8 & 1,346 & 152 & 1,587 & 179 \\
\hline
\end{tabular}

* We assume that almost all cervical cancer cases are caused by HPV infection, and thus almost $100 \%$ of cervical cancer cases are attributable to HPV infection. "ICC": Invasive cervical cancer; "RC": Relative Contribution; “N": Number of new cases diagnosed of cervical cancer each year.

Estimated number of new ICC cases is based on GLOBOCAN 2008 estimates and World Population Prospects (2010 revision). Impact of vaccination has not been taken into account for the calculations of 2025 projections.

Specific information on HPV 6 and 11 is not included due to low relative contribution of these types.

28.6\%; $\mathrm{p}<0,0001)$. Despite the consistency on the overall $\mathrm{RC}$ of the $9 \mathrm{HPV}$ types observed in ICC, large variations between articles were observed for CIN2/3 or HSIL lesions, with RCs of the $7 \mathrm{HR}$ HPV types ranging from $58.8 \%$ to 93.6\%. Individual information on LR HPV 6/11 was available in 10 studies. Addition of HPV 6/11 did not modify the CIN2/3 or HSIL burden estimates (less than 1\%).

\section{Discussion}

We provided information on HPV distribution of 9 types included in a broad spectrum vaccine currently under development for 10 regions of the world and across different grades of cervical lesions. Although existing vaccines cover HPV 16/18 that are responsible of $70 \%$ of ICC worldwide, the inclusion of HR HPV 31/33/45/52/ 58 would increase the protection to almost $90 \%$ of the infections responsible for ICC.

As previously reported, HPV 16 is uniformly the most common HPV type in all histological types of cervical cancer and all the regions of the world $[7,17]$. Our findings confirmed the regional variations in the RCs of ICC due to each specific HPV type, with the most important differences observed in Eastern Asia, where HPV 52/58 are identified in more than $10 \%$ of cases, and the higher frequency of HPV 33 in Europe (6\%), HPV 31 in South America (7\%) and HPV 45 in Africa (10\%) [7,17,22,23].

$\mathrm{RC}$ estimations in Africa from ICC study reflect that $52 \%$ of ICC cases were infected with an HPV type different from HPV 16. The different RCs on HPV genotypes in Africa are not fully understood. Different RCs may be related to host genetic determinants or could be the result of a different distribution on HPV types in HIV-infected women compared to that of the general population $[24,25]$. In Africa it should also be remarked the importance of HPV 35, identified in 5\% of ICC cases in this region and ranking as the fourth most frequent type after HPV 16/18/45.

Our data confirm that HPV 16 is the most common type in all cervical lesions. By contrast, HPV 18/45 are underrepresented in HPV-positive women with precancerous cervical lesions compared to the high contribution in ICC, where these types are consistently the second and third most common types in most of the world regions $[6,7,17]$. Recent published data in high grade cervical lesions are in agreement with the reported results from Guan et al. meta-analysis, and suggests the representativeness of the study data [26].

It should be remarked that HPV 16/18/45 were detected at younger ages in ICC compared to other HPV types. Particularly for HPV 18/45, the detection at younger ages together with the underrepresentation in precancerous cervical lesions suggest a rapid progression to ICC of both HPV types, with or without transition through preinvasive stages $[27,28]$.

Due to the restricted genotype contribution in the pathogenesis of ADC subtype, higher rates of protection with the vaccine could be expected, compared to SCC (95.5\% vs $89.1 \%$, respectively). Similar to previous findings a greater contribution of HPV 18/45 in ADC, ADSCC, and other histologies (such as neuroendocrine tumours) was observed compared to that in SCC and conversely, HPV 16 RC was higher in SCC [6,29-31]. Our data showed that HPV 16/18/ 45 were responsible for more than $94 \%$ of ADC. Much higher contributions of HPV 31/33/52/58 were observed in 


\begin{tabular}{|c|c|c|c|}
\hline & ASCUS & & CIN1 \\
\hline HPV16 & H $22.9 \%$ & HPV16 & म $27.6 \%$ \\
\hline HPV52 & $10.1 \%$ & HPV52 & H $13.8 \%$ \\
\hline HPV31 & H $9.4 \%$ & HPV31 & $11.3 \%$ \\
\hline HPV18 & H $9.0 \%$ & HPV58 & H $9.6 \%$ \\
\hline HPV58 & $7.7 \%$ & HPV18 & + $9.1 \%$ \\
\hline HPV33 & $H 6.0 \%$ & HPV33 & H $6.1 \%$ \\
\hline HPV45 & H $5.8 \%$ & HPV45 & H $4.2 \%$ \\
\hline
\end{tabular}

\begin{tabular}{l|rl} 
& \multicolumn{2}{c}{ LSIL } \\
\cline { 3 - 3 } HPV16 & & H $25.1 \%$ \\
HPV31 & H $9.5 \%$ & \\
HPV18 & H $8.7 \%$ \\
HPV52 & H $8.1 \%$ \\
HPV58 & H $7.1 \%$ \\
HPV33 & H $6.1 \%$ \\
HPV45 & H $4.6 \%$
\end{tabular}

\begin{tabular}{l|c} 
& \multicolumn{2}{c}{ CIN2 } \\
HPV16 & \\
HPV52 & 39.9\% \\
HPV58 & $16.4 \%$ \\
HPV31 & $12.1 \%$ \\
HPV18 & $11.6 \%$ \\
HPV33 & $10.0 \%$ \\
HPV45 & $-4.3 \%$ \\
H. & $5.0 \%$
\end{tabular}

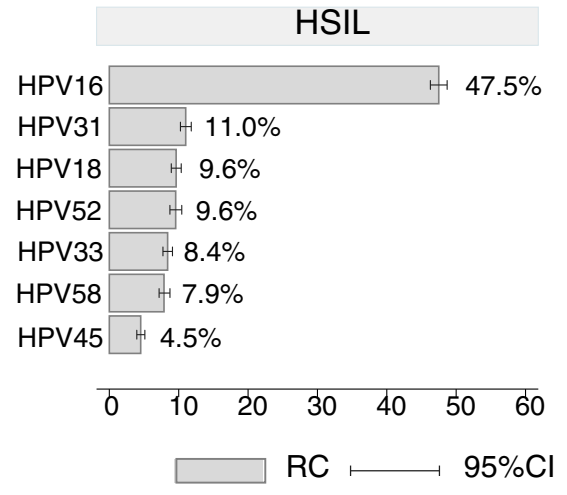

Graphs by cytological diagnosis

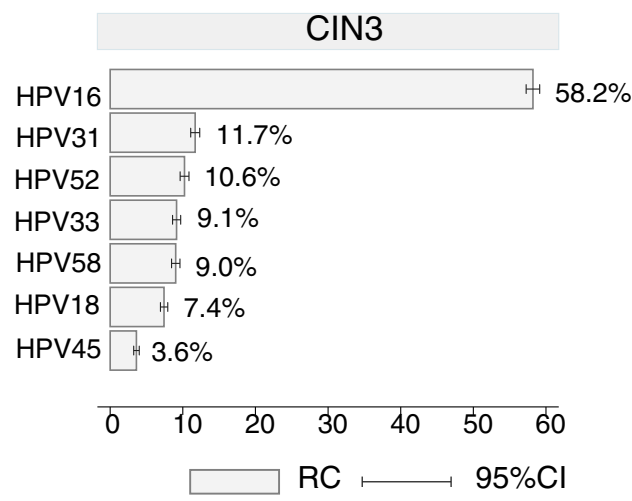

Graphs by histological diagnosis

Figure 3 Relative contribution of HPV 16/18/45/31/33/52/58 in precancerous cervical lesions HPV-positive, by histological and cytological diagnosis. "CIN1": Cervical intraepithelial neoplasia grade 1; "CIN2": Cervical intraepithelial neoplasia grade 2; "CIN3": Cervical intraepithelial neoplasia grade 3 (including squamous carcinoma in situ); "ASCUS": Atypical squamous cells of undetermined significance; "LSIL": Low-grade squamous intraepithelial lesion; "HSIL": High-grade squamous intraepithelial lesion; "RC": Relative Contribution; "95\%Cl": 95\% Confidence Interval. Additional information: HPV type specific relative contribution: Numerator = includes either single or multiple infections, thus the total sum of \% can exceed 100\%; Denominator = "Tested" cases that stands for the HPV/DNA positive cases from studies testing for the HPV type in question, thus denominators vary by type. The data source does not give specific information for HPV 6 and 11. 17. Data from Guan et al., IJC, 2012.

SCC (RC: $13.6 \%$ ) and ADSCC (RC: $7.2 \%)$ compared to the $\mathrm{RC}$ of less than $1 \%$ observed in ADC cases. Only $4.5 \%$ of ADC cases were due to HPV types not included in the nine-valent vaccine. Therefore, this broad spectrum vaccine could help to reduce the increasing rates of cervical ADC reported in the last decades in some countries with established screening programmes, which is in keeping with the relative inability of cytological screening to reduce the rates of invasive ADC [32-34].

The existence of multiple infections complicates the estimation of the attribution of cases to HPV types.
Assessment of RC of multiple infections was possible for ICC lesions, where multiple infections were added to single types in accordance with a proportional weighting attribution. We also calculated a more conservative RC by combining single type infections and multiple type infections restricted to the exact combination of the 9 mentioned types obtaining a RC close to $86 \%$ worldwide, meaning that the HPV types included in the nine-valent vaccine could cover the majority of infections responsible of ICC.

No similar attribution of multiple infections could be performed for precancerous cervical lesions from Guan 
Table 3 HPV 16/18/31/33/45/52/58 type-specific relative contribution in precancerous cervical lesions HPV-positive, by region

\begin{tabular}{|c|c|c|c|c|c|c|c|}
\hline \multirow[t]{2}{*}{ Region } & \multirow{2}{*}{$\begin{array}{l}\text { HPV } \\
\text { type }\end{array}$} & \multicolumn{3}{|c|}{ Low grade } & \multicolumn{3}{|c|}{ High grade } \\
\hline & & HPV-positive & $\mathrm{RC}$ & $95 \% \mathrm{Cl}$ & HPV-positive & $\mathrm{RC}$ & $95 \% \mathrm{Cl}$ \\
\hline \multirow[t]{7}{*}{ Africa } & HPV-16 & 517 & 16.8 & $(13.7-20.3)$ & 251 & 30.3 & $(24.7-36.4)$ \\
\hline & HPV-18 & 517 & 8.3 & $(6.1-11.0)$ & 251 & 9.2 & (5.9-13.4) \\
\hline & HPV-31 & 432 & 6.5 & $(4.4-9.2)$ & 245 & 8.2 & $(5.0-12.3)$ \\
\hline & HPV-33 & 517 & 8.5 & $(6.3-11.3)$ & 235 & 8.9 & $(5.6-13.3)$ \\
\hline & HPV-45 & 432 & 4.4 & $(2.7-6.8)$ & 245 & 4.1 & $(2.0-7.4)$ \\
\hline & HPV-52 & 432 & 11.8 & $(8.9-15.2)$ & 245 & 11.0 & (7.4-15.6) \\
\hline & HPV-58 & 517 & 10.8 & (8.3-13.8) & 251 & 11.2 & $(7.5-15.7)$ \\
\hline \multirow[t]{7}{*}{ Eastern Asia } & HPV-16 & 2,790 & 21.1 & $(19.6-22.6)$ & 3,693 & 37.9 & (36.4-39.5) \\
\hline & HPV-18 & 2,790 & 8.3 & $(7.3-9.4)$ & 3,693 & 7.4 & $(6.5-8.3)$ \\
\hline & HPV-31 & 2,552 & 4.4 & $(3.7-5.3)$ & 3,596 & 6.9 & $(6.1-7.8)$ \\
\hline & HPV-33 & 2,790 & 5.0 & $(4.2-5.8)$ & 3,693 & 9.9 & $(9.0-11.0)$ \\
\hline & HPV-45 & 2,549 & 1.2 & $(0.8-1.7)$ & 3,148 & 2.0 & $(1.6-2.6)$ \\
\hline & HPV-52 & 2,624 & 18.2 & $(16.8-19.8)$ & 3,469 & 21.3 & $(20.0-22.7)$ \\
\hline & HPV-58 & 2,781 & 13.5 & $(12.3-14.9)$ & 3,647 & 19.6 & $(18.3-20.9)$ \\
\hline \multirow[t]{7}{*}{ Western/Central Asia } & HPV-16 & 237 & 30.8 & $(25.0-37.1)$ & 79 & 68.4 & $(56.9-78.4)$ \\
\hline & HPV-18 & 237 & 6.8 & $(3.9-10.7)$ & 79 & 6.3 & $(2.1-14.2)$ \\
\hline & HPV-31 & 229 & 4.4 & $(2.1-7.9)$ & 63 & 23.8 & $(14.0-36.2)$ \\
\hline & HPV-33 & 210 & 7.1 & $(4.1-11.8)$ & 31 & 9.7 & $(2.0-25.8)$ \\
\hline & HPV-45 & 189 & 2.1 & $(0.6-5.8)$ & 28 & 7.1 & $(0.9-23.5)$ \\
\hline & HPV-52 & 72 & 2.8 & $(0.3-9.7)$ & 20 & 0.0 & $(0.0-16.8)$ \\
\hline & HPV-58 & 189 & 6.4 & $(3.3-10.8)$ & 28 & 10.7 & $(2.3-28.2)$ \\
\hline \multirow[t]{7}{*}{ South/Central America } & HPV-16 & 2,692 & 25.1 & $(23.5-26.8)$ & 1,896 & 52.9 & $(50.6-55.1)$ \\
\hline & HPV-18 & 2,690 & 6.8 & $(5.9-7.9)$ & 1,886 & 9.4 & $(8.2-10.9)$ \\
\hline & HPV-31 & 2,504 & 5.2 & $(4.4-6.1)$ & 1,837 & 10.6 & $(9.2-12.1)$ \\
\hline & HPV-33 & 2,517 & 7.5 & $(6.5-8.6)$ & 1,776 & 6.5 & $(5.3-7.7)$ \\
\hline & HPV-45 & 2,166 & 4.5 & $(3.7-5.5)$ & 1,669 & 4.8 & $(3.8-5.9)$ \\
\hline & HPV-52 & 2,127 & 5.1 & $(4.2-6.1)$ & 1,587 & 6.3 & $(5.2-7.6)$ \\
\hline & HPV-58 & 2,220 & 6.9 & $(5.8-8.0)$ & 1,589 & 9.5 & $(8.1-11.1)$ \\
\hline \multirow[t]{7}{*}{ North America } & HPV-16 & 5,532 & 24.7 & $(23.6-25.6)$ & 4,598 & 56.7 & $(55.3-58.2)$ \\
\hline & HPV-18 & 5,532 & 9.5 & $(8.7-10.3)$ & 4,598 & 9.6 & $(8.8-10.5)$ \\
\hline & HPV-31 & 5,532 & 8.9 & $(8.1-9.6)$ & 4,598 & 13.1 & $(12.1-14.1)$ \\
\hline & HPV-33 & 5,317 & 4.2 & $(3.7-4.8)$ & 4,598 & 7.6 & $(6.9-8.4)$ \\
\hline & HPV-45 & 5,415 & 5.6 & $(5.0-6.2)$ & 4,397 & 4.8 & $(4.2-5.5)$ \\
\hline & HPV-52 & 4,839 & 10.7 & (9.9-11.6) & 4,205 & 10.3 & (9.4-11.3) \\
\hline & HPV-58 & 5,213 & 7.6 & $(6.9-8.3)$ & 4,397 & 6.8 & $(6.1-7.6)$ \\
\hline \multirow[t]{7}{*}{ Europe } & HPV-16 & 14,319 & 25.9 & $(25.2-26.6)$ & 8,348 & 54.4 & (53.3-55.5) \\
\hline & HPV-18 & 14,256 & 9.1 & $(8.6-9.6)$ & 8,214 & 7.7 & $(7.2-8.3)$ \\
\hline & HPV-31 & 13,166 & 12.5 & $(12.0-13.1)$ & 7,930 & 12.4 & $(11.6-13.1)$ \\
\hline & HPV-33 & 13,186 & 6.6 & $(6.2-7.1)$ & 7,844 & 9.4 & $(8.7-10.0)$ \\
\hline & HPV-45 & 10,472 & 4.6 & $(4.2-5.1)$ & 6,244 & 3.8 & $(3.3-4.3)$ \\
\hline & HPV-52 & 9,577 & 8.3 & $(7.8-8.9)$ & 6,067 & 7.2 & $(6.6-7.9)$ \\
\hline & HPV-58 & 10,489 & 6.7 & $(6.2-7.2)$ & 6,278 & 5.8 & $(5.2-6.4)$ \\
\hline
\end{tabular}


Table 3 HPV 16/18/31/33/45/52/58 type-specific relative contribution in precancerous cervical lesions HPV-positive, by region (Continued)

\begin{tabular}{lllccccc}
\hline Oceania & HPV-16 & 385 & 24.7 & $(20.5-29.3)$ & 924 & 53.9 & $(50.6-57.2)$ \\
& HPV-18 & 385 & 8.6 & $(6.0-11.8)$ & 924 & 9.6 & $(7.8-11.7)$ \\
& HPV-31 & 385 & 13.3 & $(10.0-17.0)$ & 924 & 12.3 & $(10.3-14.6)$ \\
& HPV-33 & 385 & 5.7 & $(3.6-8.5)$ & 924 & 7.9 & $(6.2-9.8)$ \\
HPV-45 & 385 & 6.5 & $(4.3-9.4)$ & 924 & 4.2 & $(3.0-5.7)$ \\
HPV-52 & 385 & 11.4 & $(8.4-15.0)$ & 924 & $(10.2-14.5)$ \\
& HPV-58 & 385 & 9.1 & $(6.4-12.4)$ & 924 & $(4.4-7.6)$ \\
\hline
\end{tabular}

Low-grade, includes ASCUS, LSIL and CIN1; High-grade, includes HSIL, CIN2 and CIN3.

"RC": Relative Contribution; "95\%Cl": 95\% Confidence Interval.

Additional information: HPV type specific relative contribution: Numerator = includes either single or multiple infections, thus the total sum of \% can exceed

$100 \%$; Denominator = "Tested" cases that stands for the HPV/DNA positive cases from studies testing for the HPV type in question, thus denominators vary by

type.

The data source does not give specific information for HPV 6 and 11.

17. Data from Guan et al., IJC, 2012.

et al. meta-analysis, meaning that HPV positive women with multiple infections could be counted more than once. Hence RCs for precancerous lesions was shown only for individual, and not combinations of HPV types. Although this approach does not allow to estimate type specific risk, it can be useful to identify HPV variations by region or lesion severity, as it has been confirmed that HPV type is the strongest factor that affects the risks of progression of precancerous cervical lesions given viral persistence, with HPV 16 and 18 less likely to regress than other HPV types [34].

CIN2/3 lesions rarely occur in absence of HR HPV infections $[26,34,35]$, but this has not been confirmed in lower grades of cervical lesions. Data from Guan et al. meta-analysis reveal that only $52 \%$ of ASCUS cases were positive for HPV DNA compared to the more than $85 \%$ of positivity in CIN2/3 or HSIL lesions. We tried to estimate the combined RC of the $7 \mathrm{HR}$ HPV types altogether for CIN2/3 or HSIL lesions similar to that in ICC obtaining a wide range from $58.8 \%$ to $93.6 \%$., but due to the limitations of study designs, data should be interpreted cautiously and further research is needed to provide solid estimations taking into account attribution of multiple infections.

For estimations of HPV attributable cases, we assumed that current incidence rates will apply in the future, and calculated expected numbers using the appropriate population forecast. We did not take into account the impact of screening programs and current vaccines that will influence future rates since this type of analysis is more suitable for more complex analysis such as simulation models. Particularly for HPV vaccines it has to be taken into consideration that vaccination programs are not implemented worldwide, the coverage is still very low (especially in low income countries) and the impact on the reduction of invasive lesions will need more than ten years to be observable. The overall $\mathrm{RC}$ was used as the world AF. Even weighting regional estimations by world populations, the world attributable number of cases did not differ. Irrespective of changing risk, demographic changes will have a major impact in the future burden of ICC and this will be especially remarkable in developing countries where, in general incidence and mortality rates have been relatively stable over decades, reflecting the lack of screening implementation [32]. These estimates can help decision-makers evaluate the potential impact of existing and future vaccines worldwide providing an estimation of the proportion of HPV related cancer that could be avoided if the populations become immune to the 9 types of HPV included in the vaccine.

The good concordance of HPV estimations with previous reports suggests the representativeness of the study data, and especially in those regions with large sample sizes. Eighty five percent of all ICC from the ICC study were positive for DNA, compared to the ninety percent estimated in the most recent IARC meta-analysis on ICC available in the literature [6]. Given that HPV is accepted as a necessary cause of ICC, the negativity of both studies is expected to be related to technical reasons, but also to the quality of the biological specimen.

The low number of cases in the ICC study from Oceania and North America could be a potential limitation. Although RCs for Oceania are similar to that observed in previous reports, estimations of RCs for North America based on this study differ to that observed in the IARC meta-analysis and the largest study performed in this region by Wheeler et al. [6,36], with higher rates for HPV 16 (72\% vs 55\% and 53\% respectively) and lower for HPV 18 (7\% vs $18 \%$ and $13 \%$ respectively). RC for the other HPV types included in the vaccine was similar between studies. A possible explanation could be the different year of diagnosis of the cases. Wheeler et al. observed that the proportion of HPV 16 positive cases declined with more recent calendar year of diagnosis. On the other hand, estimates from the meta-analysis and Wheeler et al. study 
are based on all cases and not on HPV DNA positive cases. In order to assess these differences we recalculated estimations for North America using all tested women as a denominator and although RC of HPV 16 decreased, it was still higher in the included ICC study.

Irrespective of histological type and similar to previous reports [37], HPV 16/18/45 were identified in younger women more than other HPV types. Combined with the low proportion of ICC cases attributable to HPV types not included in the nine-valent broad spectrum vaccine, it suggests that such intervention would imply a drastic reduction of screening intervention in vaccinated cohorts.

\section{Conclusions}

The inclusion of additional HPV types in nine-valent vaccine currently under development could have direct implications for cervical cancer incidence and prevention in all regions of the world. If the nine-valent vaccine achieves the same degree of efficacy as has been shown for HPV 16 and 18, and vaccination programs are effectively implemented, almost the $90 \%$ of ICC cases worldwide could be prevented. This means that Globocan 2008 world incidence rates could be substantially reduced. If all our estimations are true, and assuming high vaccination coverage and no HPV type replacement, this intervention would provide a higher impact than any screening programme has ever produced in the very best scenarios.

\section{Competing interests}

GMC has no potential conflict of interest. BS and ST: Institutional support: HPV vaccine trials and epidemiological studies sponsored by GlaxoSmithKline, Merck and Sanofi Pasteur MSD. LA: Institutional support: HPV vaccine trials and epidemiological studies sponsored by GlaxoSmithKline, Merck and Sanofi Pasteur MSD. Personal support: Travel grants to conferences occasionally granted by Merck and Sanofi Pasteur MSD. LB: Institutional support: HPV vaccine trials and epidemiological studies sponsored by GlaxoSmithKline, Merck and Sanofi Pasteur MSD. Travel grants to conferences occasionally granted by Sanofi Pasteur MSD. TW: Is currently working at Merck. FXB: Institutional support: HPV vaccine trials and epidemiological studies sponsored by GlaxoSmithKline, Merck and Sanofi Pasteur MSD. Personal support: Travel grants to conferences / symposia / meetings and honorarium are occasionally granted by either GlaxoSmithKline, Merck, Sanofi Pasteur MSD, Roche or Qiagen. SS: Institutional support: HPV vaccine trials and epidemiological studies sponsored by GlaxoSmithKline, Merck and Sanofi Pasteur MSD. Personal support: Travel grants to conferences / symposia / meetings are occasionally granted by either GlaxoSmithKline, Sanofi Pasteur MSD or Qiagen.

\section{Authors' contributions}

BS, LA and ST were responsible for the data analysis. All authors contributed to the writing of the manuscript and BS was responsible for the preparation of the manuscript for submission. All authors read and approved the final manuscript.

\section{Acknowledgements}

All the contributors of samples, DDL and the Steering Commitee members for the RIS HPV TT study and the authors of papers for the systematic review. Data from invasive cervical cancer derived from the RIS HPV TT study group: 1) Algeria: Doudja Hammouda (National Institute of Health, Registre des Tumeurs d'Alger); Anissa Bouhadef (C.H.U Hussein-Dey- Hospital Nafissa Hamoud).
2) Argentina: Silvio Alejandro Tatti, Susana Vighi (Hospital de Clinicas "José de San Martín". Universidad de Buenos Aires. Sociedad Argentina de Patología).

3) Australia: Suzanne M. Garland, Sepher Tabrizi (The Royal Women's Hospital, The University of Melbourne).

4) Bangladesh: Ashrafun Nessa, AJE Nahar Rahman, Faruk Ahmed, Mohammad Kamal (Bangabandhu Sheikh Mujib Medical University - BSMMU).

5) Bosnia Herzegovina: Ermina Iljazovic (University Clinical Center Tuzla BiH). 6) Brazil: Marcus Aurelho de Lima, Sérgio Henrique de Almeida (Laboratório de Anatomia Patologia e citologia S/C Ltda., Associaçao de Combate ao Cancer do Brasil Central, Hospital Hélio Angotti, PATMED).

7) Chile: Rodrigo Prado (Facultad de Medicina, Universidad de Chile, Centro de Oncología Preventiva), Ximena Rodriguez ( Hospital de San José). 8) China: You Lin Qiao, Chen Wen, Wu Su Hui (CICAMS, Cancer Institute, Chinese Academy of Medical Sciences and Pekin Union Medical College). 9) Colombia: Hector Jaime Posso (Liga Contra el Cáncer de Bogotá), Luis Eduardo Bravo, Tito Collazos, Luz Stella García (Hospital Universitario del Valle), Raul Murillo, Gustavo Adolfo Hernández Suárez, Carlos Eduardo Pinzón (Instituto Nacional de Cancerología), Gloria Inés Sánchez (Universidad de Antioquía). 10)Croatia: Magdalena Grce, Ivan Sabol (Rudjer Boskovic Institutem), Sonja Dzebro, Mara Dominis (Clinical Hospital Merkur), Damir Damir Babic (University Hospital Center Zagreb).

11)Czech Republic: Vladimir Vonka (Institute of Haematology), Ivo Steiner (Faculty of Medicine and Faculty Hospital, Hradec Kralove), Václav Mandys (Third Faculty of Medicine and Faculty Hospital King's Wineyards).

12)France: Christine Clavel (Chu Reims, Laboratoire Pol Bouin, Hôpital Maison Blanche), Massimo Tommasino (International Agency for Research Cancer). 13)Greece: Maria Tzardi (Medical School of University of Crete), Theodoros Agorastos (Aristotle University of Thessaloniki).

14)Guatemala: Edgar Kestler, Luis Estuardo Lombardi, Obdulia Salic (Centro de Investigación Epidemiológica en Salud Sexual y

Reproductiva-CIESAR, Hospital General San Juan de Dios), Walter Guerra (Instituto Nacional del Cáncer), Hesler Morales (Instituto Guatemalteco de Seguridad Social, Instituto Nacional del Cáncer), Sergio Marroquin, Victor Argueta ( Hospital General San Juan de Dios).

15)Honduras: Annabelle Ferrera (Universidad Autónoma de Honduras), Ricardo Bulnes (Hospital General San Felipe).

16)India: Asha Jain (Cancer Prevention and Relief Society Raipur), Neerja Bhatla, Manju Aron, Sandeep Mathur ( All India Institute of Medical Sciences), PSA Sarma (BSP Hospital), Sushil K Giri ( Regional Cancer Center); Maheep Bhalla (JLN Hospital \& Research Center), Bharat Patel (Lab One). 17)Italy: Luciano Mariani, Ferdinando Marandino (Regina Elena Cancer Institute).

18)Japan: Toshiyuki Sasagawa (Kanazawa University Hospital). 19)South Korea: Hai-Rim Shin, Jung -II Suh, Jin-Kyung Oh (National Cancer Center), Seo -Hee Rha ( Dong-A University), Kang Chang-Suk (Asan Medical Center)

20)Kuwait: Waleed Fahad Al-Jassar (Maternity Hospital, Obstetric and Gynaecologic Department).

21)Lebanon: Muhidueddine Seoud (The American University of Beirut Medical Center).

22)Mexico: Patricia Alonso de Ruiz, Gustavo Lastra, Alma Karina Olivares Montano ( Hospital General de México).

23)Mozambique: Clare Menendez, Cleofé Romagosa(Hospital Clinic),

Carla Carrilho (Eduardo Mondlane University).

24)Nigeria: Adekunbiola Banjo, Rose Anorlu, Fatimah B. Abdulkareem, A.O Daramola, CC Anunobi (Lagos University Teaching Hospital Idi-Araba). 25)Paraguay: Elena Kasamatsu, Francisco Perrota (Instituto de Investigaciones en Ciencias de la Salud).

26)Perú: Carlos Santos, Eduardo Cáceres, Henry Gómez, Juvenal Sanchez, Carlos Vallejos, Santiago Sologuren (Instituto Nacional de Enfermedades Neoplásicas).

27)The Philippines: Celia Ladines Llave, Jean Anne Toral (Cervical Cancer Prevention Center - CECAP, Cancer Institute); Efren J. Domingo, Maria Julieta V. Germar, Jerico Thaddeus P. Luna, Arnold M. Fernandez, Carolyn Zalameda Castro, Roslyn Balacuit (University of The Philippine College of Medicine). 28)Portugal: Eugenia Cruz (Centro Regional de Oncologia Coimbra, Instituto Português de Oncologia); Manuela Lacerda,

Manuel Sobrinho-Simoes

(Institute of Molecular Pathology and Immunology of the University of Porto); Ana Felix, Jorge Manuel Soares (Instituto Portugues de Oncologia de Lisboa Francisco Gentil). 
29)Spain: Enrique Lerma (Hospital de la Santa Creu i Sant Pau); Antonio Llombart-Bosch, Morelva Toro de Méndez (Facultad de Medicina, Universidad de Valencia); Belen Lloveras (Hospital del Mar); Ana Puras Gil, Rosa Guarch (Hospital Virgen del Camino); Miguel Andújar (Complejo Hospitalario Universitario Insular Marteno-Infantil); Jaume Ordi (CRESIB - Hospital Clínic); Adela Pelayo (Clinica San Carlos); Julio Velasco, Cristina Pérez (Hospital San Agustín, \& IUOPA (Oncologic and Universitary Institute of Principality of Astúrias)); Maria Alejo (Hospital General de I'Hospitalet); Laia Alemany, F. Xavier Bosch, Ignacio G. Bravo, Vanesa Camón, Xavier Castellsagué, Omar Clavero, Silvia de Sanjosé, Ana Esteban, J.M. Godinez, Yolanda Florencia, JoEllen Klaustermeier, Nubia Muñoz, Bea Quirós, Cristina Rajo, Sara Tous, Marleny Vergara (IDIBELL, Institut Català d'Oncologia (ICO) - Catalan Institute of Oncology).

30)Taiwan: Chou Cheng-Yang (National Cheng Kung University Medical College, Taiwan Association of Gynecologic Oncologists); Tang-Yuan Chu (Buddhist Tzuchi Genral Hospital); Kuo-Feng Huang (Chi Mei Medical Center); Cheng Wen-Fang ( National Taiwan University Hospital); Chih- Ming HO (Gynecologic Cancer Center, Cathay General Hospital).

31)Thailand: Saibua C. Bunnag Chichareon, Kobkul Tungsinmunkong (Prince of Songkla University).

32)The Netherlands: Chris C.J.L.M Meijer, P.J.F Snijders (University Hospital Vrije Universiteit); Wim G.V. Quint, Daan Geraets, Nuria Guimerà, Jan Paul Brunsveld and Anco Molijn ( DDL Diagnostic Laboratory).

33)Turkey: Alp Usubutun (Hacettepe University).

34)Uganda: Michael Odida (Uganda Makere University), Elisabete Weiderpass (Karolinska Institutet, Sweden; The Norwegian Cancer Registry, Norway; Samfunded Folkhalsan, Finland).

35)United States of America: Esther Oliva (Massachusetts General Hospital); T Wright (New York Presbyterian Hospital, Columbia University Medical). 36)Venezuela: Enrique López Loyo ( Sociedad Venezolana de Patología); Victoria García Barriola, Mirian Naranjo de Gómez, Adayza Figueredo, Janira Navarro (Universidad Central de Venezuela).

37)Participants of the Pilot study: Thomas Iftner (Tubingen University, Germany), Chris J.M. Meijer and Peter Sneijders (University Hospital Vrije Universiteit), The Netherlands), Massimo Tomassino (IARC, France), Janet Kornegay (Roche, USA), Patti Gravitt (John Hopkins, USA), Wim Quint (DDL Diagnostic Laboratory, The Netherlands).

\section{Funding}

The analysis here presented has been supported by Merck \& Co, Inc. Data use for this analysis partially derived from the RIS HPV study that had received funds from: Spanish public grants from the Instituto de Salud Carlos III (grants FIS PI030240, FIS PI061246, RCESP C03/09, RTICESP C03/10, RTIC RD06/0020/0095 and (IBERESP), from the Agència de Gestió d'Ajuts Universitaris i de Recerca (AGAUR 2005SGR 00695), the Marató de TV3 Foundation (051530), and from GlaxoSmithKline Biologicals, Sanofi Pasteur MSD \& Merck \& Co, Inc., who had no role in the data collection, analysis or interpretation of the results.

\section{Author details}

${ }^{1}$ Unit of Infections and Cancer (UNIC), Cancer Epidemiology Research Program (CERP), IDIBELL, Institut Català d'Oncologia (ICO) - Catalan Institute of Oncology, Gran Via de l'Hospitalet, 199-203, L'Hospitalet de Llobregat, Barcelona, Spain. ${ }^{2}$ CIBER Epidemiología y Salud Pública, CIBERESP, Pamplona, Spain. ${ }^{3}$ International Agency for Research on Cancer Lyon, France. ${ }^{4}$ Global Health Outcomes, Merck \& Co., Inc., West Point, PA, Barcelona, Spain.

Received: 26 October 2012 Accepted: 17 December 2012 Published: 29 December 2012

\section{References}

1. Ferlay J, Shin HR, Bray F, Forman D, Mathers C, Parkin DM: GLOBOCAN 2008 v1.2, Cancer Incidence and Mortality Worldwide: IARC CancerBase No. 10 [Internet]. Lyon, France: International Agency for Research on Cancer; 2010. Available at: http://globocan.iarc.fr [Accessed on April 2012].

2. Walboomers JM, Jacobs MV, Manos MM, Bosch FX, Kummer JA, Shah KV, Snijders PJ, Peto J, Meijer CJ, Muñoz N: Human papillomavirus is a necessary cause of invasive cervical cancer worldwide. J Pathol 1999, 189(1):12-19.
3. IARC Monographs on the Evaluation of Carcinogenic Risks to Humans: Vol 100, A Review of Human Carcinogens. Part B: Biological Agents. Lyon, France: International Agency for Research on Cancer; 2011.

4. World Health Organization (WHO): Human papillomavirus vaccines WHO position paper. Geneva: World Health Organization; 2009. Available at: http://www.who.int/wer/2009/wer8415.pdf [Accessed on April 2012]

5. Stanley M: HPV - immune response to infection and vaccination. Infect Agent Cancer 2010, 5:19.

6. Li N, Franceschi S, Howell-Jones R, Snijders PJ, Clifford GM: Human papillomavirus type distribution in 30,848 invasive cervical cancers worldwide: Variation by geographical region, histological type and year of publication. Int J Cancer 2011, 128(4):927-935.

7. de Sanjose S, Quint WG, Alemany L, Geraets DT, Klaustermeier JE, Lloveras B, Tous S, Felix A, Bravo LE, Shin HR, Vallejos CS, de Ruiz PA, Lima MA, Guimera N, Clavero O, Alejo M, Llombart-Bosch A, Cheng-Yang C, Tatti SA, Kasamatsu E, Iljazovic E, Odida M, Prado R, Seoud M, Grce M, Usubutun A, Jain A, Suarez GA, Lombardi LE, Banjo A, et al: Human papillomavirus genotype attribution in invasive cervical cancer: a retrospective cross-sectional worldwide study. Lancet Oncol 2010, 11(11):1048-1056.

8. Garland SM, Steben M, Sings HL, James M, Lu S, Railkar R, Barr E, Haupt RM, Joura EA: Natural history of genital warts: analysis of the placebo arm of 2 randomized Phase III trials of a quadrivalent human papillomavirus (types 6, 11, 16, and 18) vaccine. J Infect Dis 2009, 199(6):805-814.

9. Romanowski B: Long-term protection against cervical infection with the human papillomavirus. Hum Vaccin 2011, 7(2):161-169.

10. Kane MA, Serrano B, de Sanjose S, Wittet S: Implementation of HPV immunization in the developing world. Vaccine 2012, 30(Suppl 5):F192-200

11. GAVI Alliance: GAVI Alliance Press releases. 17 November 2011. Available at: http:// www.gavialliance.org/library/news/press-releases/2011/gavi-takes-first-steps-tointroduce-vaccines-against-cervical-cancer-and-rubella/ [Accessed on April 2012]

12. Kane MA: Preventing Cancer with Vaccines: Progress in the Global Control of Cancer. Cancer Prev Res (Phila) 2012, 5(1):24-9.

13. Kim JJ, Brisson M, Edmunds WJ, Goldie SJ: Modeling cervical cancer prevention in developed countries. Vaccine 2008, 26(Suppl 10):K76-86.

14. Goldie SJ, O'Shea M, Diaz M, Kim SY: Benefits, cost requirements and cost-effectiveness of the HPV16,18 vaccine for cervical cancer prevention in developing countries: policy implications. Reprod Health Matters 2008, 16(32):86-96.

15. Brotherton JM, Gertig DM: Primary human prophylactic human papillomavirus vaccination programs: future perspective on global impact. Expert Rev Anti Infect Ther 2011, 9(8):627-39.

16. Merk\&Co.; Inc: Annual report. 2012. Available at: http://www.merck.com/ investors/financials/form-10-k-21011.pdf. [Accessed on April 2012].

17. Guan P, Howell-Jones R, Li N, Bruni L, de Sanjosé S, Franceschi S, Clifford GM: Human papillomavirus (HPV) types in 115,789 HPV-positive women: a meta-analysis from cervical infection to cancer. Int J Cancer 2012, 131(10):2349-2359.

18. Insinga RP, Liaw KL, Johnson LG, Madeleine MM: A systematic review of the prevalence and attribution of human papillomavirus types among cervical, vaginal, and vulvar precancers and cancers in the United States. Cancer Epidemiol Biomarkers Prev 2008, 17(7):1611-22.

19. Wentzensen N, Schiffman M, Dunn T, Zuna RE, Gold MA, Allen RA, Zhang R, Sherman ME, Wacholder S, Walker J, Wang SS: Multiple human papillomavirus genotype infections in cervical cancer progression in the study to understand cervical cancer early endpoints and determinants. Int J Cancer 2009, 125(9):2151-8.

20. United Nations: Department of Economic and Social Affairs, Population Division. World Population prospects; 2011. the 2010 revision. Available at: http://esa.un.org/wpp/unpp/panel_population.htm [Accessed on April 2012].

21. Smith JS, Lindsay L, Hoots B, Keys J, Franceschi S, Winer R, Clifford GM: Human papillomavirus type distribution in invasive cervical cancer and high-grade cervical lesions: A meta-analysis update. Int J Cancer 2007, 121(3):621-32

22. Parkin DM, Louie KS, Clifford G: Burden and trends of type-specific human papillomavirus infections and related diseases in the Asia Pacific region. Vaccine 2008, 26(suppl 12):M1-16.

23. Parkin DM, Almonte M, Bruni L, Clifford G, Curado MP, Pineros M: Burden and trends of type-specific human papillomavirus infections and related diseases in the latin America and Caribbean region. Vaccine 2008, 26(suppl 11):L1-15. 
24. Denny LA, Franceschi S, de Sanjosé S, Heard I, Moscicki AB, Palefsky J: Human Papillomavirus, Human Immunodeficiency Virus and Immunosuppression. Vaccine 2012, 30(Suppl 5):F168-74.

25. Strickler HD, Palefsky JM, Shah KV, Anastos K, Klein RS, Minkoff H, Duerr A Massad LS, Celentano DD, Hall C, Fazzari M, Cu-Uvin S, Bacon M, Schuman P, Levine AM, Durante AJ, Gange S, Melnick S, Burk RD: Human papillomavirus type 16 and immune status in human immunodeficiency virus-seropositive women. J Natl Cancer Inst 2003, 95(14):1062-71.

26. Hariri S, Unger ER, Powell SE, Bauer HM, Bennett NM, Bloch KC, Niccolai LM, Schafer S, Steinau M, Markowitz LE, the HPV-IMPACT Working Group: Human papillomavirus genotypes in high grade cervical lesions in the United States. J Infect Dis 2012, 206(12):1878-1886.

27. Safaeian M, Schiffman M, Gage J, Solomon D, Wheeler CM, Castle PE: Detection of precancerous cervical lesions is differential by human papillomavirus type. Cancer Res 2009, 69(8):3262-6.

28. Muñoz N, Hernandez-Suarez G, Méndez F, Molano M, Posso H, Moreno V, Murillo R, Ronderos M, Meijer C, Muñoz A, Instituto Nacional de Cancerología HPV Study Group: Persistence of HPV infection and risk of high-grade cervical intraepithelial neoplasia in a cohort of Colombian women. Br J Cancer 2009, 100(7):1184-90.

29. Clifford G, Franceschi S: Members of the human papillomavirus type 18 family (alpha-7 species) share a common association with adenocarcinoma of the cervix. Int J Cancer 2008, 122(7):1684-5.

30. Wang HL, Lu DW: Detection of human papillomavirus DNA and expression of $\mathrm{p} 16, \mathrm{Rb}$, and $\mathrm{p} 53$ proteins in small cell carcinomas of the uterine cervix. Am J Surg Pathol 2004, 28(7):901-8.

31. Herrington CS, Graham D, Southern SA, Bramdev A, Chetty R: Loss of retinoblastoma protein expression is frequent in small cell neuroendocrine carcinoma of the cervix and is unrelated to HPV type. Hum Pathol 1999, 30(8):906-10.

32. Vizcaino AP, Moreno V, Bosch FX, Muñoz N, Barros-Dios XM, Parkin DM: International trends in the incidence of cervical cancer: $I$, Adenocarcinoma and adenosquamous cell carcinomas. Int J Cancer 1998, 75(4):536-45.

33. Bray F, Carstensen B, Møller H, Zappa M, Zakelj MP, Lawrence G, Hakama M, Weiderpass E: Incidence trends of adenocarcinoma of the cervix in 13 European countries. Cancer Epidemiol Biomarkers Prev 2005, 14(9):2191-9.

34. Schiffman M, Castle PE, Jeronimo J, Rodriguez AC, Wacholder S: Human papillomavirus and cervical cancer. Lancet 2007 370(9590):890-907.

35. Prétet JL, Jacquard AC, Saunier M, Clavel C, Dachez R, Gondry J, Pradat P, Soubeyrand B, Leocmach Y, Mougin C, Riethmuller D, EDiTH study group: Human papillomavirus genotype distribution in low-grade squamous intraepithelial lesions in France and comparison with $\mathrm{CIN} 2 / 3$ and invasive cervical cancer: the EDITH III study. Gynecol Oncol 2008, 110(2):179-84

36. Wheeler CM, Hunt WC, Joste NE, Key CR, Quint WG, Castle PE: Human papillomavirus genotype distributions: implications for vaccination and cancer screening in the United States. J Natl Cancer Inst 2009, 101(7):475-87.

37. Muñoz N, Bosch FX, Castellsagué X, Díaz M, de Sanjose S, Hammouda D, Shah KV, Meijer CJ: Against which human papillomavirus types shall we vaccinate and screen? The international perspective. Int J Cancer 2004, 111(2):278-85

doi:10.1186/1750-9378-7-38

Cite this article as: Serrano et al:: Potential impact of a nine-valent vaccine in human papillomavirus related cervical disease. Infectious Agents and Cancer 2012 7:38.

\section{Submit your next manuscript to BioMed Central and take full advantage of:}

- Convenient online submission

- Thorough peer review

- No space constraints or color figure charges

- Immediate publication on acceptance

- Inclusion in PubMed, CAS, Scopus and Google Scholar

- Research which is freely available for redistribution

Submit your manuscript at www.biomedcentral.com/submit
C) Biomed Central 